\title{
A EFICÁCIA DO PLANEJAMENTO TURÍSTICO SUSTENTÁVEL EM UNIDADES DE CONSERVAÇÃO DA NATUREZA: o caso do delta do rio Jacuí/RS
}

\section{THE EFFECTIVENESS OF SUSTAINABLE TOURISTIC PANNING IN NATURE CONSERVATION UNITS: the case of the Jacuí river delta/RS}

\author{
Cícero Castello Branco Filho \\ Pós-Doutorando do Departamento de Geografia da Universidade Federal do Rio Grande do Sul. \\ ccbf41@gmail.com \\ Luís Alberto Basso \\ Prof. Adjunto do Departamento de Geografia da Universidade Federal do Rio Grande do Sul. \\ lbasso@terra.com.br
}

\begin{abstract}
RESUMO
A hipótese fundamental da investigação faz referência direta à possibilidade de, a partir da pesquisa transdisciplinar de caráter sistêmico, identificar os problemas que afligem os espaços naturais protegidos e sugerir soluções para a gestão desses espaços, com base em um planejamento que evoque o uso turístico do território, buscando uma relação simbiótica entre os visitantes e as comunidades de destino, abrindo possibilidade à melhoria da qualidade de vida e colaborando para a conservação do ambiente nesses locais. $\mathrm{Na}$ esfera prática, com finalidade experimental e de aplicação dos conhecimentos, propusemos a análise de uma Unidade de Conservação de uso misto - o Parque e APA Estadual Delta do Jacuí/RS - onde utilizamos a técnica da etnografia como método principal de investigação. A partir dessa elaboração, o estudo identificou os principais problemas que se contrapõem ao desenvolvimento equilibrado e sustentável do território e sugeriu soluções, procurando destacar a relevância de cada um dos atores envolvidos no processo.

Palavras-Chave: Análise Sistêmica; Planejamento Turístico; Sustentabilidade; Territorialidades; Unidade de Conservação.
\end{abstract}

\section{ABSTRACT}

Employing systemic transdisciplinary studies, the fundamental hypothesis of this investigation makes a direct reference to the possibility of identifying the problems that afflict protected natural areas and suggest solutions for the management of these areas, based on planning that calls for the touristic use of the territory, in the quest for a symbolic relationship between the visitors and the destination communities, thereby creating possibilities for improving quality of life and collaborating in the conservation of the environment in these locations. In the practical sphere, with an experimental purpose and for the application of expertise, we propose the analysis of a mixed use

Geo UERJ - Ano 15, no . 24, v. 1, $1^{\circ}$ semestre de 2013 p. 85-103

ISSN: 1415-7543 E-ISSN: 1981-9021

http://www.e-publicacoes.uerj.br/index.php/geouerj 
Conservation Unit - the Jacuí River Delta State Park and EPA in Rio Grande do Sul in which we employ the ethnography technique as the main method of investigation. Based on this development, the study identified the leading problems that obstruct balanced and sustainable development of the territory and suggested solutions, striving to highlight the relevance of each of the actors involved in the process.

Key words: Systemic Analysis; Touristic Planning; Sustainability; Territorialities; Conservation Unit.

\section{INTRODUÇÃO}

O interesse da Geografia pelo fenômeno turístico desenvolveu-se de modo bastante especial e vêm alcançando um papel diferenciado no contexto de ambas as áreas do conhecimento. Com base nisso, é notório que a expansão da atividade turística, bem como a clara compreensão da sua segmentação, tem despertado a atenção de vários pesquisadores e, particularmente, dos geógrafos, graças a grande proximidade de seus objetos de estudo. Inúmeros fatores, próprios de nosso tempo, tais como a expansão das redes técnicas, o aumento do "tempo livre", o barateamento de passagens rodoviárias e aéreas, e a forte segmentação do mercado turístico explicam por que, em nível mundial, o turismo é hoje a terceira atividade econômica de maior geração de renda e emprego no mundo, responsável por mais de 7,9\% do PIB mundial (OMT, 2007). Inúmeros autores, pertencentes a diversas áreas do conhecimento, como Burkhart (1992) e Ortiz (1994), apontam o turismo como a mais promissora atividade mundial, não apenas no sentido econômico, mas também como possível artífice de um processo de qualificação sóciocultural e ambiental. Não obstante, dados demonstram que o fluxo turístico externo para o Brasil representa hoje apenas algo em torno de $0,45 \%$ do fluxo turístico mundial, o que atesta o baixo grau de inserção turística internacional do país (MTUR, 2006). Também o turismo interno é tímido em função de variáveis bem conhecidas, tais como o baixo nível de renda da população, o alto custo dos meios de transporte, carência nos níveis de segurança e de infra-estrutura, entre outros. Embora ainda persista essa realidade, é crescente o número de dados, trabalhos, pesquisas e projetos relacionados a esse setor da economia nacional. Nesse sentido, um importante segmento do turismo, e que tem crescido muito acima da média de outros segmentos do setor, é o ecoturismo, pois é visto como uma possibilidade efetiva de (re)qualificação do território, especialmente nos espaços legalmente protegidos. Assim, com a emergência do ecoturismo e das questões relacionadas à sustentabilidade, surge a necessidade de 
direcionamento do planejamento turístico ao encontro do campo mais amplo do planejamento e gestão do território, proposta desse artigo.

\section{OBJETIVO}

Este artigo visa colaborar para o desenvolvimento de estudos que sirvam de embasamento para a consolidação de uma proposta de implementação de um plano de gestão territorial em áreas legalmente protegidas com base na prática do planejamento turístico, balizado pelos princípios da sustentabilidade econômica e sócio-ambiental. A área englobada pelo delta do rio Jacuí foi escolhida como referência para experimentação prática da possibilidade de constituição de um destino turístico sustentável em uma Unidade de Conservação (UC), baseada na compatibilidade entre o uso público e a conservação do espaço.

\section{METODOLOGIA}

A metodologia inclui e prioriza o trabalho de campo, técnicas de imageamento e métodos de abordagem qualitativa. A descrição, procedimento básico de uma pesquisa qualitativa, precisa envolver a coleta de dados para responder questões a respeito do estado atual dos sujeitos do estudo, focalizando a investigação principalmente nos processos. A metodologia etnográfica adequa-se à investigação de comunidades, suas representações e aspirações. Na Geografia, essa abordagem possibilita enriquecer a análise da realidade estudada pelos geógrafos, especialmente quando se trata da realidade de uma cultura particular (Nogueira, 2003). Nesta metodologia, os procedimentos de observação participante, as entrevistas, a história oral e a história de vida são as principais técnicas e foram aqui utilizadas. A investigação procurou basearse sempre em uma visão sistêmica e histórico-crítica, pois buscam dar respostas aplicáveis a problemas percebidos na atualidade. Assim a pesquisa, tal como é próprio do método etnográfico, produziu registros visuais, mapas, entrevistas e observações, dando um caráter mais abrangente a esta estratégia que tem base participativa e qualitativa. 


\section{ÁREA DE ESTUDO}

O Delta do rio Jacuí (figura 1) abrange uma área que corresponde a uma UC de uso múltiplo (parte de proteção integral, parte de uso sustentável), impactada pela ação antrópica e permanentemente ameaçada pela ausência de planos e projetos que efetivamente possam atender as necessidades de qualificação sócio-ambiental daquele espaço. Sua área total é de 37.068 hectares dos quais 14.242 hectares ficam reservados a UC de uso restrito (Parque Estadual) e 22.826 hectares a um espaço recentemente criado de uso sustentável (APA). Esta UC abrange um total de 30 ilhas de formação sedimentar e áreas continentais do baixo Jacuí, num ambiente de grande beleza cênica, formado por um mosaico de banhados na porção interior das ilhas (pântanos marginais), campos inundáveis (na planície de inundação do rio Jacuí) e matas nas áreas de margem (diques marginais). O delta tem como ambiente predominante os banhados e toda a dinâmica ambiental deste espaço ocorre em função da ação das águas. A tentativa de proteção dessa área na forma de UC foi e continua sendo importante por diversos motivos e que envolvem questões ecológicas e sócio-culturais. Porém, apesar de todos os estudos empreendidos na compreensão daquele ambiente e dos esforços para criação e constituição de uma UC englobando aquele espaço, de fato o parque nunca chegou a ser efetivamente gerido, embora tenha sido implementado de direito. Como resultado desse descaso, o delta, nos últimos 30 anos, sofreu um processo lento e contínuo de degradação socioambiental que, na verdade, se arrasta até os dias de hoje. Neste lapso de tempo, tanto a população quanto os governos estaduais e dos cinco municípios que tem áreas situadas no interior da UC (Porto Alegre, Canoas, Triunfo, Nova Santa Rita e Eldorado do Sul) assistiram a ocorrência de todo o tipo de irregularidades na área em questão. Pesquisa desenvolvida por Branco Filho e Basso (2005) identificou no interior do parque ações danosas ao ambiente que incluíam depósitos de lixo e criação de porcos, constituição de aterros, extração irregular de areia, pesca e caça predatória, introdução de espécies exóticas, abandono de sucatas de navios e, principalmente, a ocupação irregular dos espaços. A referida investigação constatou que a principal ameaça à saúde socioambiental do delta estava exatamente na ocupação antrópica irregular. Também pelo mesmo motivo, ficou evidente que a situação institucional da 
UC era absolutamente insustentável e necessitava de urgente reavaliação. As ameaças ao ecossistema privilegiado do delta se revelaram com a falta completa de ações de fiscalização, planejamento e planos de gestão. Em função disso, se materializaram sérios problemas sociais e ambientais como, por exemplo, a ocupação desenfreada infligida por milhares de pessoas que ergueram desde moradias precárias, a casas luxuosas em áreas que, segundo a lei, não poderiam receber nenhum morador ou empreendimento permanente ou provisório. Assim, as estimativas mais conservadoras indicam que 15 mil pessoas habitam hoje o local.

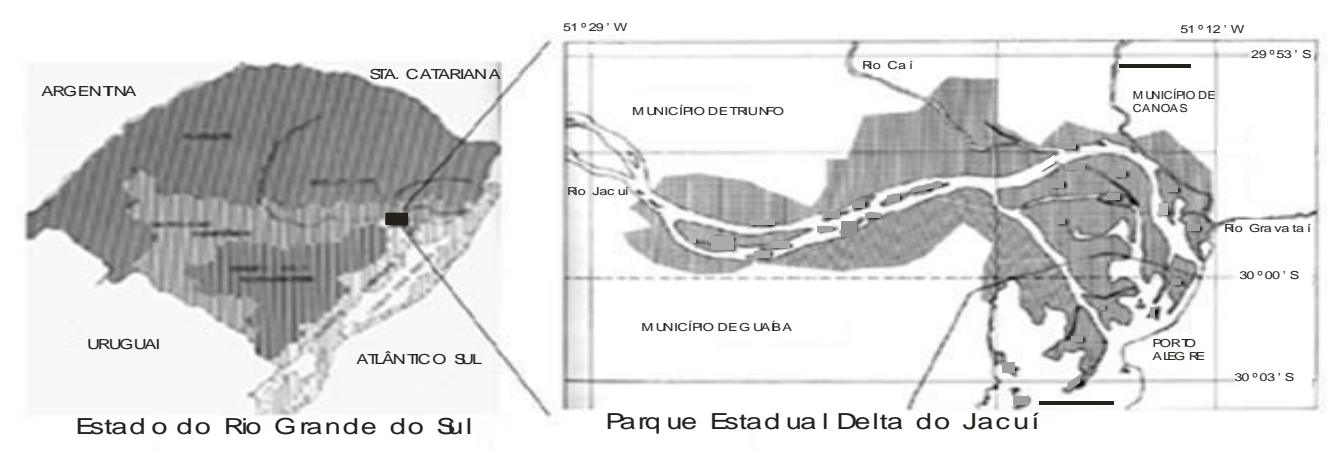

Figura 1- Localização do delta do rio Jacuí no Estado do Rio Grande do Sul.

\section{Turismo, participação e valorização das comunidades locais}

Neste artigo, optamos por privilegiar abordagens de planejamento e gestão do espaço que tenham como principal preocupação a conservação ambiental e a proteção e inclusão das comunidades locais no processo efetivo de constituição de um destino turístico sustentável. Para Barreto (2003), um dos paradigmas do desenvolvimento turístico sustentável é a base local, motivo pelo qual o conceito de "comunidade" é importante. A partir da definição proposta por Melver (apud Ávila et al., 2001) uma comunidade "consiste em um círculo de pessoas que vivem juntas, que permanecem juntas de sorte que buscam não este ou aquele interesse particular, mas um conjunto inteiro de interesses, suficientemente amplo e completo de modo a abranger suas vidas.”

Nessa perspectiva, a abordagem comunitária é uma das que se destacam, já que corresponde a uma estratégia de planejamento que busca envolver as populações 
locais ou receptoras no processo de tomada de decisão. Assim, quem planeja deve ter a versatilidade de desenvolver programas coerentes tanto com as filosofias culturais, sociais e econômicas do governo (o planejamento turístico não acontece sem a esfera política), quanto com os interesses dos habitantes da região de destino, não esquecendo a satisfação dos visitantes e preservando a estrutura sociocultural dos autóctones. Entretanto, a pesquisa identificou que os maiores problemas para a implementação desta abordagem estão ligados, justamente, à política do processo de planejamento e às divergências que podem surgir na estrutura governamental, principalmente em se tratando de áreas legalmente protegidas, pois nesses locais, muitas vezes, a administração, além de ser consorciada, deve se ater à legislação específica que tem como principal função, evitar ou minimizar impactos socioambientais nessas áreas. Em outras palavras, tanto os impactos no ambiente físico, quanto os socioculturais gerados pelo turismo, talvez sejam o principal aspecto a ser considerado quando da elaboração de um plano para a atividade. Yázigi (1999) faz a seguinte reflexão: “De pouco adianta que uma localidade entre na frente turística se, simultaneamente, não estiver combatendo seus adversários: a pobreza, a degradação do território, as tecnologias erradas ou o mau uso da memória”. O importante aqui é perceber e reconhecer que o planejamento turístico comunitário é um processo sistêmico e dinâmico, que exige propostas de intervenção que reflitam as exigências de grupos de interesse diversos, valores da comunidade e da sociedade e o contexto socioeconômico-ambiental em que ocorre. Outro fator de destaque é o fato de não haver nenhuma "receita" préestabelecida para a implementação de propostas de desenvolvimento sustentável da atividade. Por sinal, isto é um dos grandes fatores responsáveis pelo fracasso de muitas tentativas de se levar o desenvolvimento territorial através da atividade turística. Em verdade, cada situação exige uma solução específica na escala e no contexto do local. Assim, as experiências nos mostram que, em projetos em que o envolvimento comunitário se deu de forma mais efetiva, houve uma melhora significativa com relação à preservação do patrimônio, tanto natural, como cultural. É importante ter em mente que o desenvolvimento do turismo sustentável exige paciência, dedicação e comprometimento de longo prazo envolvendo, concomitantemente, os agentes da gestão do espaço turístico, quais sejam, o Estado, a iniciativa privada, a comunidade local e o próprio turista.

Geo UERJ - Ano 15, no . 24, v. 1, $1^{\circ}$ semestre de 2013 p. 85-103 ISSN: 1415-7543 E-ISSN: 1981-9021 http://www.e-publicacoes.uerj.br/index.php/geouerj 


\section{O Delta do rio Jacuí: uma avaliação prática da eficácia do turismo como atividade indutora do desenvolvimento territorial local em Áreas Protegidas}

Para a elaboração de qualquer tipo de planejamento territorial, é pressuposto indispensável o conhecimento e a compreensão detalhada da realidade local/conjuntural do espaço alvo da investigação. Para isso, se faz necessário tanto o entendimento atualizado dos elementos concretos que compõem o espaço, a dinâmica da ocupação e o uso do território, quanto a compreensão de como se dá o sistema de relações da sociedade local com as áreas de entorno e as instituições públicas e privadas que coordenam sua dinâmica territorial e, em última análise, decidem e encaminham destinações funcionais de uso do espaço. Tendo isto em vista, o delta do rio Jacuí, embora seja, em grande parte, território do município de Porto Alegre, constituindo, inclusive, um de seus bairros mais peculiares, é curiosa a constatação de que são poucos os cidadãos que, de fato, reconhecem este ambiente diferenciado, atentando para suas belezas, sua importância ecológica, sua vocação natural para o turismo e pesquisa científica, bem como para com as ameaças que sobre ele pairam. Originalmente, a área toda é composta por um ecossistema delicado como, de fato, é característico dos ambientes úmidos tais como unidades palustres representadas por áreas pantanosas ou de banhados. Todo esse espaço é habitado por uma fauna e flora ainda bastante rica e diversificada (considerando-se a extensão da área, sua localização latitudinal e seu atual grau de ocupação/impactação antrópica), adaptadas a ambientes extremamente úmidos e planos, mas que vem sofrendo alterações em função da introdução de espécies exóticas, queimadas, agropecuária, poluentes diversos, caça e outros impactos ambientais. $\mathrm{O}$ geossistema regional propiciou uma geologia local totalmente associada à constituição de depósitos deltáicos constituídos por solos aluviais e de glei húmico e por solos orgânicos, de natureza argilosa, onde, por vezes, a geologia natural está associada a elaborações tecnogênicas (Valente, 1999). É importante considerar que, se neste local as características geológicas sempre foram um forte elemento de impedimento à ocupação do espaço pela sociedade, a composição pedológica/geomorfológica, por sua vez, propiciou um início de ocupação tradicional do espaço, proporcionando o uso agrícola em algumas áreas de solo glei e ocupação humana nas áreas marginais, naturalmente mais elevadas (foto 1). Posteriormente, a constituição de inúmeros aterramentos 
artificiais, intensificou muito a ocupação, alterando a utilização do solo e o ordenamento espacial, sendo hoje motivo de permanente preocupação, tanto com o ambiente físico quanto com a qualidade de vida de quem lá habita. De acordo com a contagem populacional realizada pela FIBGE (1996), foi constatado um total de 14.500 habitantes na área onde hoje se encontra a UC de uso misto. O quadro 1 relaciona os municípios integrantes da área, o número de domicílios e a população residente.

\begin{tabular}{|c|c|c|c|c|}
\hline \multirow{2}{*}{ MUNICÍPIO } & \multirow{2}{*}{ DOMICÍLIOS } & \multicolumn{3}{|c|}{ POPULAÇÃO } \\
\cline { 3 - 5 } & & Homens & Mulheres & Total \\
\hline Charqueadas & 68 & 157 & 123 & 280 \\
\hline Canoas & 297 & 565 & 516 & 1.081 \\
\hline Eldorado do Sul & 537 & 961 & 945 & 1.906 \\
\hline Nova Santa Rita & 963 & 1.704 & 1.674 & 3.378 \\
\hline Porto Alegre & 2.176 & 3.872 & 3.831 & 7.703 \\
\hline Triunfo & 461 & 826 & 798 & 1.624 \\
\hline TOTAL & 4.115 & 7.314 & 7.186 & 14.500 \\
\hline
\end{tabular}

Quadro 1: Contagem Populacional dos habitantes do PEDJ,1996 - FIBGE

A diversidade cultural que ocorre na área deltaica está diretamente vinculada ao modo como se deu a ocupação daquele espaço. Os processos diferenciados de ocupação acabaram por gerar um sistema de múltiplos territórios que, estando situados em uma área legalmente protegida e relativamente restrita, atesta a complexidade dessa análise. Os elementos culturais nesse estudo são importantes na medida em que refletem os diferentes modos de vida dos núcleos comunitários ali identificados. A pesquisa demonstrou que esse fator acaba por refletir diretamente na percepção ambiental dos habitantes, bem como nas suas expectativas e projeções a respeito do futuro do seu local de vivência e das possibilidades a ele vinculadas. Foi possível identificar pelo menos três ramos culturais bastante distintos, quais sejam aqueles vinculados à ocupação tradicional do espaço, o das populações de alta/média renda e, ainda, aqueles de baixa ou sem nenhuma renda fixa. As comunidades vinculadas a esses matizes socioculturais podem ser especialmente identificadas na figura 2 e no quadro 2, elaborados com base na pesquisa etnográfica e que demonstra as diferentes formas de ocupação mapeadas naquele espaço, baseadas, por sua vez, em um processo histórico de ocupação/apropriação que nos remete a variadas formas de territorialização em escala 
local. A comunidade tradicional está localizada principalmente na parte insular, preponderantemente na ilha da Pintada e, pontualmente, em algumas outras ilhas, tais como a das Flores, do Lage e Grande dos Marinheiros, além de em Eldorado do Sul, especificamente ao longo do Canal da Pintada. Basicamente, se identificam como pescadores e artesãos, descendentes de portugueses provenientes da ilha de Açores, cuja tradição pesqueira é muito forte. Não há dados numéricos precisos sobre estes habitantes, porém, é certo que trata-se de uma ocupação antiga, iniciada no século XVIII e, ainda hoje, com características muito peculiares, baseada numa percepção diferenciada do ambiente local.

\begin{tabular}{|c|c|c|c|}
\hline & Ocupação Tradicional & $\begin{array}{c}\text { Ocupação de alta renda / } \\
\text { Urbana }\end{array}$ & $\begin{array}{c}\text { Ocupação de baixa } \\
\text { renda }\end{array}$ \\
\hline \begin{tabular}{|l} 
Modo de \\
vida/Vínculos \\
Culturais
\end{tabular} & $\begin{array}{l}\text { Áreas úmidas } \\
\text { Pesca/artesanato } \\
\text { Agricultura (arrozeiros; } \\
\text { subsistência) } \\
\text { Cultura açoriana }\end{array}$ & \begin{tabular}{|l} 
Urbano \\
Consumismo \\
Lazer
\end{tabular} & $\begin{array}{l}\text { Misto de urbano e rural } \\
\text { "Cultura" do lixo; } \\
\text { Catadores; } \\
\text { Carroceiros }\end{array}$ \\
\hline $\begin{array}{l}\text { Processo de } \\
\text { Ocupação }\end{array}$ & $\begin{array}{l}\text { Antigo - colonização séc } \\
\text { XVIII. }\end{array}$ & $\begin{array}{l}\text { Recente - a partir do final } \\
\text { da década de } 1960 \text { com } \\
\text { forte ampliação nos anos } \\
\text { 1970/80. } \\
\end{array}$ & $\begin{array}{l}\text { Recente }- \text { a partir da } \\
\text { implementação do } \\
\text { complexo rodoviário. }\end{array}$ \\
\hline $\begin{array}{l}\text { Concentração } \\
\text { Atual }\end{array}$ & $\begin{array}{l}\text { Essencialmente na ilha da } \\
\text { Pintada e em alguns } \\
\text { pontos da ilha das Flores, } \\
\text { do Lage, Grande do } \\
\text { Marinheiros e de } \\
\text { Eldorado do Sul. }\end{array}$ & $\begin{array}{l}\text { Ao longo do Canal do } \\
\text { Jacuí; ao sul da BR-290 na } \\
\text { Ilha G. dos Marinheiros; } \\
\text { Ponta sul da ilha do Pavão } \\
\text { e setores continentais em } \\
\text { Eldorado do Sul e Sans } \\
\text { Souci. }\end{array}$ & $\begin{array}{l}\text { Nas áreas continentais } \\
\text { de Canoas, Eldorado e } \\
\text { Nova Sta Rita e } \\
\text { insulares, nas ilhas do } \\
\text { Pavão, G. dos } \\
\text { Marinheiros, Flores e } \\
\text { Pintada. Nas margens } \\
\text { da rodovia BR-290. } \\
\end{array}$ \\
\hline $\begin{array}{l}\text { Atividade } \\
\text { Econômica }\end{array}$ & $\begin{array}{l}\text { Pesca e Artesanato } \\
\text { Trabalhos domésticos } \\
\text { Setor terciário. }\end{array}$ & $\begin{array}{l}\text { As mais variadas: política, } \\
\text { empresarial, profissionais } \\
\text { liberais, etc., quase sempre } \\
\text { ligadas à cidade. }\end{array}$ & $\begin{array}{l}\text { Agricultura de } \\
\text { subsistência } \\
\text { Criação de animais } \\
\text { Reciclagem e reuso do } \\
\text { lixo urbano. }\end{array}$ \\
\hline $\begin{array}{l}\text { Percepção } \\
\text { Ambiental }\end{array}$ & $\begin{array}{l}\text { Conhecem o ambiente } \\
\text { em detalhes: os } \\
\text { caminhos, fauna, flora e a } \\
\text { história local. }\end{array}$ & \begin{tabular}{|l} 
Conhecem o ambiente \\
superficialmente e o \\
utilizam essencialmente \\
com finalidades de lazer e \\
divertimento. \\
\end{tabular} & $\begin{array}{l}\text { Conhecem o ambiente } \\
\text { apenas pontualmente e } \\
\text { não guardam vínculos } \\
\text { com as áreas úmidas. }\end{array}$ \\
\hline $\begin{array}{l}\text { Percepção em } \\
\text { relação ao } \\
\text { Turismo }\end{array}$ & $\begin{array}{l}\text { Acreditam na atividade } \\
\text { como motor do } \\
\text { desenvolvimento local e } \\
\text { alternativa de renda às } \\
\text { novas gerações, apesar do } \\
\text { desalento com antigos } \\
\end{array}$ & $\begin{array}{l}\text { Em geral, entende que o } \\
\text { ambiente é ideal para a } \\
\text { atividade, mas temem uma } \\
\text { "invasão" turística local } \\
\text { (turismo de massa). }\end{array}$ & $\begin{array}{l}\text { Só vislumbram a } \\
\text { possibilidade na } \\
\text { hipótese de geração } \\
\text { imediata de renda e } \\
\text { emprego. Não possuem } \\
\text { qualificação para } \\
\end{array}$ \\
\hline
\end{tabular}

Geo UERJ - Ano 15, no. 24, v. 1, $1^{\circ}$ semestre de 2013 p. 85-103 ISSN: 1415-7543 E-ISSN: 1981-9021 http://www.e-publicacoes.uerj.br/index.php/geouerj 
DOI: $10.12957 /$ geouerj.2013.5173

projetos que fracassaram.

exercer a atividade.

Quadro 2 - Quadro síntese das diferentes concepções do espaço das comunidades associadas ao delta. 


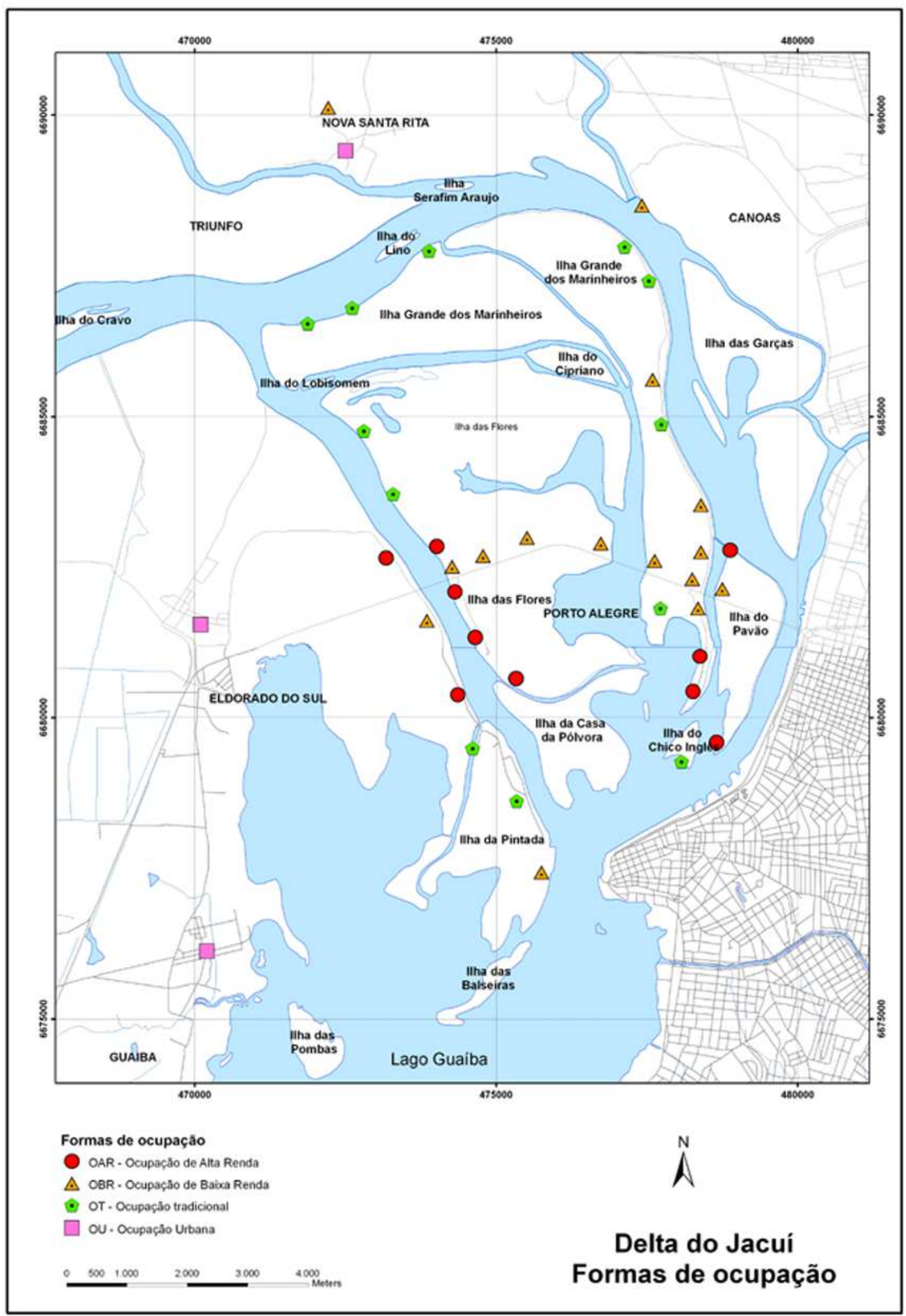

Figura 2

Geo UERJ - Ano 15, no ${ }^{\circ}$ 24, v. 1, $1^{\circ}$ semestre de 2013 p. 85-103

ISSN: 1415-7543 E-ISSN: 1981-9021

http://www.e-publicacoes.uerj.br/index.php/geouerj 
Os demais tipos de comunidades ali estabelecidas possuem uma visão do ambiente e uma dinâmica socioeconômica completamente diferenciada das comunidades que historicamente habitam aquele ambiente (ocupação tradicional do espaço). Culturalmente, não possuem nenhum vínculo com a pesca/artesanato, nem com as histórias e lendas (que são muitas) associadas aos ilhéus e ao seu ambiente. O processo de ocupação é recente, posterior a instalação do complexo rodoviário e a origem majoritária desses ocupantes é a RMPA ou o interior do Estado. A ocupação de alta renda (foto 10) teve início no final da década de 1960 e apresentou forte incremento ao longo dos anos de 1970/80, estando, hoje, consolidada e parcialmente regularizada pela instauração da APA, que deu-se a partir do ano de 2005. As mansões situam-se sempre junto à margem do lago, no espaço insular e continental, ao longo dos canais e sobre os diques marginais, que foram completamente modificados. Em uma visão mais detalhada, se localizam dos dois lados do canal do Jacuí, em Eldorado do Sul e na ilha das Flores, em trechos da ilha da Pintada, e na ilha Grande dos Marinheiros, ao sul da rodovia. Nesse ambiente, seu modo de vida está vinculado a atividades de lazer, como passeios de lancha, jet sky, remo e outras atividades náuticas ou de lazer de alta renda. Sua cultura é associada ao consumismo característico da sociedade capitalista contemporânea e suas práticas e ações naquele espaço foram altamente prejudiciais à cultura tradicional e, sobretudo, ao ambiente local. Já, as populações de baixa renda (foto 11) ocupam hoje áreas continentais nos municípios de Canoas, Eldorado e Nova Sta Rita, além de extensões significativas na ilhas das Flores, sobretudo ao longo da BR-116/290, na ilha do Pavão, ilha Mauá e Grande dos Marinheiros, ao norte da ponte, num dos núcleos de mais baixa renda do delta, contrastando com as mansões na mesma ilha, situadas ao sul da ponte (fotos 1e 2).

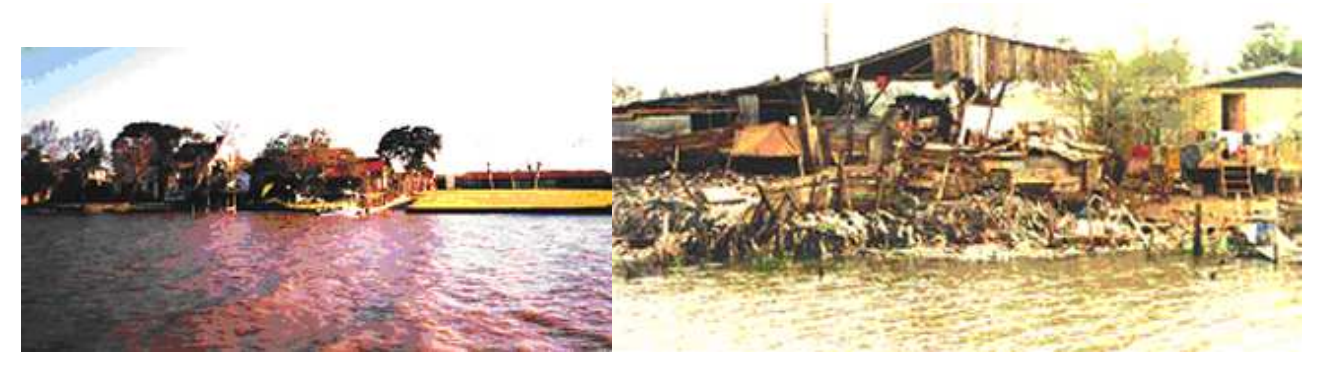

Fotos 1 e 2 - Flagrante do contraste entre os tipos de ocupação em diferentes setores da ilha Grande dos Marinheiros. Fonte: Branco Filho, C. C., 1999. 
Também, ao longo de toda a travessia rodoviária por sobre o delta (cerca de 8km), ocorre a ocupação de baixa renda. Branco Filho e Basso (2005) constataram que grande parte dessa população é oriunda da RMPA e do interior do Estado. O motivo de ocuparem áreas irregularmente e impróprias para habitação é socioeconômico, em função da baixa condição social, da falta de oportunidades e espaço nas cidades e da expulsão do campo. Essa população se caracteriza por sua extrema vulnerabilidade social, não possuindo nenhum vínculo com ambientes úmidos ou com atividades aquáticas e vivendo, basicamente, da criação de animais, da pequena agricultura e, sobretudo, das atividades vinculadas à reciclagem do lixo urbano, sua principal fonte de subsistência. Assim, essa população se encontra culturalmente deslocada e socialmente marginalizada. As diferenças culturais marcantes (explicitadas na tabela XX) evidenciam a necessidade de uma articulação entre as atividades de planejamento e gestão, com vistas à atividade turística, a fim de que esta tenha a oportunidade de desenvolver-se com sustentabilidade em todos os níveis. Porém, este processo, perpassa, necessariamente, pela compreensão dos entraves que inviabilizam uma qualificação daquela UC, via setor do turismo, sem o conhecimento do qual não é possível pensar o espaço ou mesmo projetar qualquer proposta de qualificação sobre ele.

Neste momento, é importante perceber que no Brasil as áreas protegidas, principalmente os Parques Nacionais, Estaduais e APAs, estão entre as principais destinações de ecoturismo, com a anuência da legislação ambiental brasileira, através do SNUC e SEUC, que contemplam a prática controlada dessas atividades nestes ambientes diferenciados. A atividade ecoturística possui forte interesse na divulgação e consolidação de valores éticos protecionistas referentes ao meio natural, pois dessa forma a atividade agrega mais um aliado no processo de sua continuidade. Assim, em termos éticos, tanto o conjunto de leis quanto a índole do ecoturista parecem estar alinhados, no sentido prático, com os modelos de turismo comprometidos com os pressupostos da sustentabilidade ambiental. Apesar disso, há localidades onde, tanto as questões éticas, quanto as políticas e econômicas não conseguem atingir um grau de interesse e organização necessários ao desenvolvimento de projetos sustentáveis. Neste momento, o conjunto da nossa pesquisa demonstra que a área englobada pelo delta do Jacuí, sem nenhuma dúvida, se enquadra nesse aspecto da análise. Inúmeros empecilhos, muitos considerados históricos, funcionam como um poderoso limitador a 
qualquer processo de efetivação de um projeto real de desenvolvimento local, baseado na atividade turística. Dentre esses empecilhos, a pesquisa identificou os seguintes:

- o não cumprimento da legislação;

- a ausência de Plano de Manejo;

- os conflitos na esfera político-administrativa;

- a falta de interação dos conhecimentos socioambientais e territoriais;

- a baixa taxa de escolaridade, nível de vida e déficit de informações a cerca do território;

- centralização e burocratização.

\section{Estratégia de viabilização do projeto turístico para o território do Delta do Jacuí}

O Turismo, enquanto fruto de atividades e práticas sociais, está subordinado a uma série de ações e interesses, sem os quais a sua sistematização no espaço não acontece. Assim, o interesse de uma eventual efetivação da atividade depende, em grande parte, da percepção manifesta dos agentes locais, a saber, o poder público, a iniciativa privada e a comunidade local, pois é na escala local que o turismo se manifesta territorialmente, com a constituição do "lugar turístico" (Fratucci, 2000).

Seguindo a trilha metodológica, foi nossa intenção buscar a percepção dos principais agentes que atuam permanentemente na área do Delta do Jacuí, a fim de melhor compreender as reais possibilidades de constituição de um destino turístico naquele espaço, tendo em vista ser ele uma UC com todas aquelas características socioambientais aqui já relatadas. Assim, a partir do universo de entrevistas realizadas, constatou-se que a ampla maioria dos entrevistados se manifestaram favoráveis à elaboração de um plano de constituição de um destino turístico, no espaço relativo à UC mista representada pelo delta do rio Jacuí. Assim, com relação à visão do turista, foram feitas 4 seções de entrevistas, em embarcações que levam visitantes para realizar passeios no delta. As entrevistas, informais e não estruturadas, foram realizadas em datas e dias da semana diferentes. Sempre foram entrevistados $10 \%$ dos visitantes presentes no passeio fluvial, resultando em um total de 26 entrevistas. Deste montante, 20 pessoas ficaram satisfeitas com o tipo de passeio e o recomendariam. Vinte e três pessoas entenderam que o local é ótimo para a prática do turismo e 16 pessoas gostariam que houvesse a oportunidade de um trecho turístico pelas ilhas, com guias, para contato com a história do local e com os produtos da comunidade tradicional.

Geo UERJ - Ano 15, no . 24, v. 1, $1^{\circ}$ semestre de 2013 p. 85-103

ISSN: 1415-7543 E-ISSN: 1981-9021

http://www.e-publicacoes.uerj.br/index.php/geouerj 
Usamos esses números para comprovar que o visitante, sem dúvida, possui, se estimulado e envolvido no processo de planejamento, o desejo de conhecer não só a natureza do local, mas as culturas a ela associadas. É importante relatar que houve muitas críticas também, as quais destacamos, por exemplo, a ausência de guias, mapas e informações a respeito da fauna e flora local; a baixa oferta de itinerário nos trajetos náuticos e a impossibilidade de um passeio mais longo, com parada em uma das ilhas.

Constata-se que o notório interesse público no desenvolvimento do turismo local vai ao encontro da atual legislação nacional para o setor. O Plano Nacional de Turismo - PNT - apresenta, para a esfera local, métodos de inserção da atividade, onde as principais estratégias estão explícitas em seu texto e, resumidamente, visam:

- a proteção do ambiente natural e do patrimônio histórico e cultural, com desenvolvimento sustentado, melhoria na qualidade de vida e desenvolvimento local;

- a diminuição das desigualdades regionais/locais, com maior aporte de divisas para os pólos receptivos, vinculado à geração de empregos na esfera local;

- a formação de mão-de-obra e de um produto turístico competitivo; inclusive com possibilidade de inserção nacional/internacional;

- a satisfação do cliente;

Ainda mais especificamente, o trabalho elaborado pelo Ministério do Turismo e pelo Ministério do Meio Ambiente, dos Recursos Hídricos e da Amazônia Legal, contando com a participação de outros órgãos públicos, da iniciativa privada e ONGs, visando direcionar o desenvolvimento do ecoturismo no Brasil e, especialmente, nos espaços protegidos, destacou no documento "Diretrizes para uma Política Nacional de Ecoturismo" (Barros, 1995), nove importantes ações, identificadas como estratégicas para a consecução desses objetivos, as quais sintetizamos no quadro a seguir:

\begin{tabular}{|l|l|}
\hline $\begin{array}{l}\text { Regulamentação do } \\
\text { Ecoturismo }\end{array}$ & $\begin{array}{l}\text { Elaborar dispositivos legais necessários ao desenvolvimento do } \\
\text { ecoturismo; estabelecer mecanismos de fiscalização e controle; } \\
\text { propor regulamentações; definir responsabilidades e estabelecer } \\
\text { critérios para a priorização de áreas com potencial ecoturístico. }\end{array}$ \\
\hline $\begin{array}{l}\text { Fortalecimento e Interação } \\
\text { Institucional }\end{array}$ & $\begin{array}{l}\text { Promover a articulação e o intercâmbio de informações e de } \\
\text { experiências entre os órgãos governamentais e o setor privado. }\end{array}$ \\
\hline $\begin{array}{l}\text { Formação e Capacitação de } \\
\text { Recursos Humanos }\end{array}$ & $\begin{array}{l}\text { Fomentar a capacitação de pessoal para o desempenho de diversas } \\
\text { funções pertinentes à atividade ecoturística. }\end{array}$ \\
\hline $\begin{array}{l}\text { Controle de Qualidade do } \\
\text { Produto Ecoturístico }\end{array}$ & $\begin{array}{l}\text { Promover o desenvolvimento de metodologias, modelos e sistemas } \\
\text { para acompanhamento, avaliação e aperfeiçoamento da atividade } \\
\text { de ecoturismo, abrangendo o setor público, privado e as } \\
\text { comunidades envolvidas. }\end{array}$ \\
\hline $\begin{array}{l}\text { Gerenciamento de } \\
\text { Informações }\end{array}$ & $\begin{array}{l}\text { Realizar o levantamento de informações (inventariamento), em } \\
\text { nível nacional, regional e/ou local, visando à formação de banco } \\
\text { de dados e à obtenção de indicadores para o desenvolvimento do }\end{array}$ \\
\hline
\end{tabular}

Geo UERJ - Ano $15, \mathrm{n}^{\circ} .24$, v. 1, $1^{\circ}$ semestre de 2013 p. 85-103

ISSN: 1415-7543 E-ISSN: 1981-9021

http://www.e-publicacoes.uerj.br/index.php/geouerj 


\begin{tabular}{|l|l|}
\hline & ecoturismo. \\
\hline $\begin{array}{l}\text { Incentivos ao } \\
\text { Desenvolvimento do } \\
\text { Ecoturismo }\end{array}$ & $\begin{array}{l}\text { Promover e estimular a criação e a adequação de incentivos para o } \\
\text { aprimoramento de tecnologias e de serviços, a ampliação da infra- } \\
\text { estrutura existente e a implementação de empreendimentos } \\
\text { ecoturísticos. }\end{array}$ \\
\hline $\begin{array}{l}\text { Implantação e Adequação } \\
\text { da Infra-estrutura }\end{array}$ & $\begin{array}{l}\text { Promover o desenvolvimento de tecnologias e a implantação de } \\
\text { infra-estrutura nos destinos prioritários. }\end{array}$ \\
\hline $\begin{array}{l}\text { Conscientização e } \\
\text { Informação do Turista }\end{array}$ & $\begin{array}{l}\text { Divulgar aos turistas as atividades inerentes ao produto } \\
\text { ecoturístico e orientar a conduta adequada nas áreas visitadas. }\end{array}$ \\
\hline Participação Comunitária & $\begin{array}{l}\text { Buscar o engajamento das comunidades localizadas em destinos } \\
\text { ecoturísticos, potenciais e existentes, estimulando-as a identificar, } \\
\text { no ecoturismo, uma alternativa economicamente viável. }\end{array}$ \\
\hline
\end{tabular}

Quadro 3 - Estratégias e ações indicadas para a consecução do (eco)turismo a nível local

A respeito de todas as possibilidades aqui aventadas, é imperioso destacar a necessidade da construção de uma visão regional do turismo, o que, necessariamente, perpassa pela organização e fortalecimento das instâncias locais, como os Conselhos Municipais de Turismo, a partir da representatividade efetiva nos colegiados das organizações sociais, das entidades e empresas do trade turístico, sob observância dos órgãos oficiais. Também, a criação de um Centro de Interpretação Ambiental e de Informações Turísticas para visitantes é altamente recomendado como elemento estrutural do próprio processo de implantação de um pólo local de turismo.

\section{CONSIDERAÇÕES FINAIS}

Neste artigo, procuramos valorizar e dar ênfase à vertente do turismo ligada diretamente à sustentabilidade socioeconômica e ambiental, principalmente em função de estarmos nos referindo a espaços especialmente protegidos, ou seja, recortes especiais da superfície terrestre potencialmente ameaçados e, por isso mesmo, passíveis de um olhar diferenciado e protecionista. Em suma, almejou-se uma proposta que indicasse um caminho para a (re)qualificação do ambiente natural, preservação dos modos de vida com autonomia dos nativos e a satisfação dos visitantes. Procuramos mostrar que, nessa perspectiva, o processo de qualificação territorial local deve, necessariamente, estar baseado na valorização das comunidades, especialmente a tradicional, como de fato foi ressaltado nos trabalhos e estudos de caso analisados e que serviram de subsídio para constituição desse artigo. Esse status de valoração comunitária corresponde a um modelo administrativo em que a ética a ele associada

Geo UERJ - Ano 15, no . 24, v. 1, $1^{\circ}$ semestre de 2013 p. 85-103

ISSN: 1415-7543 E-ISSN: 1981-9021

http://www.e-publicacoes.uerj.br/index.php/geouerj 
prevê a contemplação das vivências, aprendizagens e experiências locais. Desta forma, o planejamento pode vir a permitir, por meio do seu arcabouço metodológico, um chamamento à comunidade, envolvendo-a no processo e permitindo, incondicionalmente, a sua participação direta, através dos mecanismos legais disponíveis no sistema político local.

Não obstante, constatamos que as comunidades do delta do Jacuí vêm sendo, nas últimas décadas e de variados modos, apropriadas pelo capital e desassistidas pelas políticas públicas. Assim, historicamente, reproduzem-se as relações capitalistas com reflexos nefastos para a comunidade tradicional do delta. Conforme pudemos flagrar, o processo de descaracterização desta comunidade tem sido contínuo e inclemente mas, por outro lado, percebe-se ainda que há solidariedade entre os nativos, reveladas em suas práticas cotidianas que caracterizam a cultura ribeirinha, repleta de sentidos e peculiares representações sociais, diferenciadas da cultura urbana, pois se relacionam com o uso direto da natureza, especialmente, por sua intimidade com o sistema ecológico local diferenciado. Por isto mesmo, entendemos que o turismo ecológico de base comunitária é a melhor proposta de alternativa para este espaço, substituindo a lógica exclusivamente capitalista aplicada aos grandes pólos receptores, por um modelo de gestão apoiado em uma lógica racional e construtivista, com foco na integração entre o visitante e o nativo. No entanto, revelou-se evidente que nada disso será possível sem o interesse e a participação direta do Estado. Compete a ele a responsabilidade de orientar e conscientizar as comunidades sobre os planos e políticas locais voltadas a este espaço específico. Nessa medida, é importante compreender que nada será possível sem a sua participação efetiva. Em relação a isso, vale lembrar que no Brasil, tanto a criação, quanto o manejo das UCs são de responsabilidade direta do Estado, que deve ser o condutor das políticas estabelecidas para as áreas protegidas. O Estado é o gestor legal dessas áreas, porém, essa gestão, segundo o SNUC e SEUC, deve ser realizada com a participação da sociedade civil (Júnior et al., 2009). Portanto, é também função essencial e dever do Estado conscientizar e envolver as comunidades no processo de gestão. Eis aqui, uma das principais características do desenvolvimento territorial, especialmente em UCs: a capacidade de envolvimento dos atores locais, que passam, então, a ser reconhecidos e se reconhecerem como uma comunidade real e que tem como referência primeira seu espaço de vivência, tornando-se mais ativos no processo 
de intervenção e ação sobre o território, com o intuito de promover seu desenvolvimento geral.

Enfim, as possíveis estratégias de viabilização de um projeto de valorização do espaço local focado em um turismo efetivamente sustentável para as UCs brasileiras deverão, necessariamente, respeitar importantes pressupostos, tais como o do comprometimento do poder público na sua elaboração e/ou implementação, a inclusão, participação e articulado envolvimento político das comunidades locais como premissa básica, o respeito à legislação que rege as UCs e o conhecimento contínuo, atualizado e detalhado do sistema ambiental local como parâmetro essencial para a elaboração do produto turístico final. Ao cabo, os objetivos a serem atingidos deverão estar em sintonia com os parâmetros de desenvolvimento local que visem ao equilíbrio ambiental, ao menor impacto ecológico e à preservação dos valores sociais.

\section{REFERÊNCIAS}

BARRETO, M. O imprescindível aporte das ciências sociais para o planejamento e a compreensão do turismo. Campinas: Horizontes antropológicos, 2003.

BARROS II, Silvio e Denise de la Penha. Diretrizes para uma Politica Nacional de Ecoturismo. Grupo de Trabalho Interministerial MICT/MMA. Brasília: EMBRATUR, 1995.

BRANCO FILHO, C. C. A Orla do Lago Guaíba no Município de Porto Alegre/RS: análise ambiental urbana e proposta de revitalização. Dissertação de Mestrado. Programa de Pós-Graduação em Geografia, UFRGS, 2005.

BURKHART, A. J. \& MEDLIK, S. Tourism: past, present and future. V.1, $2^{\circ}$ ed. Londres: Heinemann, 1992.

FRATUCCI, A. C. Os lugares turísticos: territórios do fenômeno turístico. Revista GEOgraphia $\mathrm{n}^{\circ}$ 4, UFF, 2000.

Instituto Brasileiro de Geografia e Estatística. Manuais Técnicos em Geociências. Manual técnico de Pedologia. IBGE, 2007.

Ministério do Turismo - MTUR. Pesquisa Anual de Conjuntura Econômica e Turismo. Disponível 
http://www.ebape.fgv.br/novidades/pdf/PesqAnualDeConjunturaEconomicadoTurismo. pdf. 2006.

NOGUEIRA, M. Sete Lagoas: a dinâmica funcional de um lugar na rede urbana de Minas Gerais. Tese de Doutorado. Instituto de Geociências. UFRJ. Rio de Janeiro, 2003. Disponível na internet em

http://www.revistas.uepg.br/index.php?journal=tp\&page=article\&op=view\&path\%5B\% $5 \mathrm{D}=336 \&$ path $\% 5 \mathrm{~B} \% 5 \mathrm{D}=237$

OMT. Estatísticas e Indicadores do Turismo Mundial. Disponível em http://www.unwto.org/index.php. 2007.

ORTIZ, R. Mundialização e cultura. São Paulo: Brasiliense, 1994.

VALENTE, A. L. S. Mapa Geotécnico do município de Porto Alegre - RS. Programa de Pós-Graduação Engenharia de Minas, Metalúrgica e dos Materiais. PPGEM/UFRGS, 1999.

Artigo recebido para publicação em março de 2013.

Artigo aceito para publicação em junho de 2013. 